\title{
A GESTÃO DE RELAÇÕES HUMANAS E AS NOVAS POSTURAS DAS EMPRESAS NAS RELAÇÕES DE TRABALHO FRENTE AO PROCESO DE GLOBALIZAÇÃO
}

\section{THE MANAGEMENT OF HUMAN RELATIONS BEINGS AND THE NEW POSITIONS OF THE COMPANIES IN THE WORK RELATIONS FRONT TO THE GLOBALIZATION PROCESS}

\author{
Marcos José Corrêa Bueno ${ }^{1}$; Alexandre Alisancic ${ }^{2}$; Oduvaldo Vendrametto ${ }^{3}$ \\ ${ }^{1}$ Universidade Bandeirantes UNIBAN - São Paulo - Brasil - mjvm@ig.com.br \\ ${ }^{2}$ Faculdade Flamingo - São Paulo - Brasil - alisancic@ bol.com.br \\ ${ }^{3}$ Universidade Paulista UNIP - São Paulo - Brasil - oduvaldov@uol.com.br
}

\begin{abstract}
Resumo
Este artigo visa abordar as alterações ocorridas na gestão de Recursos Humanos nas indústrias face à globalização e seus reflexos nas formas de relação do trabalho, considerando sua complexidade e seus conseqüentes conflitos e o crescente grau de competitividade.

Em particular, analisam-se as mudanças recentes nas relações de trabalho nas indústrias automobilísticas e de auto peças do ABC paulista, comparando-se a Administração Científica de Taylor com o atual ambiente toyotista. Estuda-se como este processo de ajuste, que se exacerbou na década de 1990, vem elucidando novas tendências nas relações de trabalho da categoria analisada, configurando-se mudanças importantes, notadamente no que se refere à relação de trabalho e suas novas exigências. Este trabalho pretende trazer algumas reflexões sobre as novas necessidades produtivas frente ao mercado competitivo, apresentando um exemplo ilustrativo, obtido com base nos resultados preliminares de uma pesquisa em andamento envolvendo empresas do setor automotivo localizadas na região da Grande São Paulo e do Grande ABC.
\end{abstract}

Palavras-chave: Trabalho; Globalização; Recursos Humanos.

\section{Introdução}

Os resultados obtidos sugerem que com o recente crescimento do capital estrangeiro investido na indústria brasileira nos últimos anos, as mudanças dos modelos de gestão em recursos humanos foram nítidas.

As multi-nacionais, inclusive as localizadas na região do Grande $\mathrm{ABC}$ Paulista apresentavam em seu alicerce administrativo modelos tradicionais trazidos desde a década de 50 e 60. Com o processo de globalização em crescimento, houve choques entre gerações dentro do ambiente de trabalho. 
Muitos destes não estavam acostumados com as novas exigências, uma vez que com o aumento do capital estrangeiro aplicado, houve conseqüente aumento do controle da aplicação deste mesmo capital, além da pressão por aumento nos resultados financeiros exigidos.

Atualmente, as empresas possuem expectativas e necessidades bem diferentes de épocas passadas e estas vêm exigindo dos profissionais uma revisão dos conceitos utilizados até então.

\section{Revisão bibliográfica}

\subsection{Taylorismo}

Considerado o fundador da Escola de Administração Científica, Frederick Winslow Taylor (1856-1915) contribuiu para a consolidação da Administração como ciência. Oriunda das ciências sociais, a Administração tem por finalidade a tentativa de aplicação dos métodos da ciência empírica aos problemas gerenciais, com o objetivo de alcançar uma elevada eficiência industrial. Taylor teve inúmeros seguidores e provocou uma verdadeira revolução no pensamento administrativo e no mundo industrial de sua época.

No entanto, esse autor é de grande importância para os estudos que se direcionam para a categoria trabalho. Ao contrário de outras abordagens, esse engenheiro, além de dar ênfase às praticas administrativas, chamou atenção para a "problemática" do movimento humano enquanto trabalho. Dessa forma, buscou racionalizar e metodizar os movimentos do operário, visando a melhoria das condições de rendimento e o aumento da produtividade.

O taylorismo - nomenclatura utilizada pelos estudiosos - tinha por objetivo prático solucionar os problemas americanos no início do século XX.

Os problemas econômicos por que passavam o país eram delegados por Taylor aos grandes desperdícios e à pequena produtividade norte-americana, que, devido à disparidade de métodos administrativos, não conseguia levar em conta os reais problemas que envolviam o ato produtivo.

$\mathrm{Na}$ busca da solução, Taylor observou que o trabalho era a chave para solucionar os problemas. Sem reservas, culpou a "vadiagem no trabalho" como causa primeira dos desperdícios e dos altos custos das indústrias americanas. Para Taylor, "O trabalhador vem ao serviço e no dia seguinte, em vez de empregar todo o seu esforço para produzir a maior soma possível de trabalho, quase sempre procura fazer menos do que pode realmente e produz muito menos do que é capaz.

O paradigma disponível neste contexto é a obra de Fayol (1958). Nela, Fayol chama a atenção para a Administração como fator preponderante. A importância não é dada às questões que envolvem a organização do trabalho no chão da fábrica, mas sim aos aspectos administrativos e de negociação. Esta obra, já considerada clássica nos círculos da administração, divide-se em duas partes. A primeira destaca a necessidade e a possibilidade de um ensino administrativo e a segunda 
refere-se aos princípios e elementos de Administração, ambos tendo por finalidade a busca de maiores rendimentos e produtividade (Taylor 1970).

\subsection{Fordismo}

Henry Ford (1863-1947), industrial americano, iniciou sua vida como mecânico de automóveis, vindo depois a ser um dos maiores fabricantes de automóveis do mundo. No final do século XIX, a indústria estava atingindo um novo nível tecnológico e econômico, quando Ford introduziu, em abril de 1913, em sua fábrica Highland Park, em Detroit, seus conceitos de produção, conseguindo reduzir, de maneira relevante, os custos na produtividade. Ford elaborou um novo perfil de produção. Os trabalhadores já não eram mais os únicos atores "privilegiados" da produção. Ford incorporou o consumidor, entendendo ser este todo aquele ator produtivo que, de uma forma ou de outra, compartilha a produção. Dessa forma, o cerne do fordismo seriam as relações entre o operário, o empregador e o consumidor. Para ele, o trabalho industrial tinha como chave a produção - representada pelo empregador e pelo operário - e o consumo - representado pelo público consumidor.

O valor dado a essas relações tinha por pressuposto básico o "trabalho para a coletividade". Essa concepção levou Ford a buscar uma maior produtividade, no intuito de atender o mercado consumidor. A inovação-chave proposta por ele foi o trabalho repetido e em série.

Ford introduziu então a produção que se movimentava. A finalidade era levar o objeto de trabalho até o operário, não precisando que esse se deslocasse em direção ao objeto produzido. Essa mudança permitiu reduzir o esforço humano na montagem e aumentar a produtividade, diminuindo os custos proporcionalmente à elevação do volume produzido.

Além disso, os seus carros eram projetados visando uma maior facilidade em sua construção e manutenção, sem precedentes na história das indústrias (Ford 1926).

\subsection{O Toyotismo}

O sistema Toyota teve sua origem na necessidade particular em que se encontrava o Japão de produzir pequenas quantidades de numerosos modelos de produtos que em seguida evoluiu para tornar-se um verdadeiro sistema de produção.

Dada sua origem, este sistema é particularmente bom na diversificação. Enquanto o sistema clássico de produção de massa planificado é relativamente refratário à mudança, o sistema Toyota, ao contrário, revela-se muito plástico; ele adapta-se bem às condições de diversificação mais difíceis (Coriat 1994). 
Este sistema necessitava de trabalhadores qualificados e motivados. Coriat (1994) argumenta a constituição do "trabalhador multifuncional", detectando um "movimento de desespecialização" dos operários profissionais e qualificados, que com o passar do tempo tornavamse, obrigatória ou necessariamente, trabalhadores multifuncionais.

A relação homem-máquina também se modificou; se no fordismo, a relação era entre um homem e uma máquina, no toyotismo, dependendo do setor de produção, a relação é de um operário para cada cinco máquinas.

O sistema flexível da Toyota levou mais de 20 anos para se colocar como método eficaz de produção. Porém, o impacto de sua introdução vem suscitando inúmeras transformações. Se, por um lado, há o aumento da produtividade, da qualidade e da rapidez quanto ao produto final, por outro, essas modificações atingem intensamente o universo do trabalhador: sua consciência, sua subjetividade, as formas de representação, de identidade e de organização, que são obrigadas a se adaptar a esse novo modelo.

O sistema Toyota também tem conseguido êxito em capitalizar as necessidades do mercado consumidor, bem como na adaptação das mudanças tecnológicas. No final dos anos 60, a Toyota já trabalhava totalmente dentro do modelo de produção flexível, disseminando suas práticas para todo o mundo. Nos anos 80, essa difusão vem assumindo uma nova roupagem nos países em que estão sendo implementadas.

\subsection{Aspectos das novas relações de trabalho}

Desde os novos modelos de gestão até as novas exigências em termos de resultados causou um impacto no ambiente que vêm sendo muito discutido em diversos níveis.

Nos últimos anos, aumentou a preocupação dos gestores com treinamento e qualificação profissional. Só para citar alguns exemplos, empresas que há 20 anos atrás possuíam em seu quadro de funcionários encarregados de produção com escolaridade muitas vezes inferior ao segundo grau (atual ensino médio), passaram a contratar engenheiros para a mesma ocupação.

Isso aconteceu devido às novas exigências no ambiente de trabalho. O funcionário que antes tinha como obrigação apenas a repetição de tarefas em série, conforme o modelo fordista de produção, atualmente é cobrado deste a criação de soluções a melhorias de resultado (maximização da produção e redução de custos).

A partir da década de 80, o modelo Toyota de produção, que se revelou superior ao fordismo por responder às necessidades de flexibilização do produto e do trabalho, se constituiu como um elemento de inovação organizacional da produção e do trabalho. 
A automação veio reduzir a exposição do trabalhador a tarefas árduas e a garantir ao empregador o controle do conhecimento sobre os processos produtivos. Por demandar do trabalhador seu raciocínio abstrato, o aumento da escolaridade formal na fábrica e a requalificação profissional passaram a ser indispensáveis nestes novos tempos. As mudanças ocorridas nos processos de trabalho não pararam na automação, mas continuaram a transformar as organizações pela adoção das técnicas de gestão ligadas à qualidade e à produtividade, a exemplo do JIT (técnicas de combate ao desperdício), tais como: Kaizen (processo de melhorias constantes), Células de Manufatura (responsabilidade compartilhada pela produção), Controle Estatístico do Processo (estudo das variações e exceções ocorridas no processo), Set-Up (tempo gasto com ajustes e troca de ferramentas) e TPM (manutenção produtiva total em busca do defeito zero), polivalência dos trabalhadores, além de exigir das empresas maior investimento em treinamento, o que levou os trabalhadores mais técnicos a tomar o lugar dos não-qualificados, contribuindo para o aumento do nível de desemprego.

O sistema toyotista previa a eliminação rígida das tarefas, mas exigia um longo treinamento e aperfeiçoamento do trabalho, valorizando a experiência do trabalhador e acabando com a rigidez e a demarcação das especialidades das tarefas. O trabalho passou a ser organizado de forma mais horizontal, integrando departamentos e setores, atribuindo aos operários a co-responsabilidade sobre os resultados a serem obtidos.

Outras mudanças que ocorreram neste período — a busca de envolvimento maior das chefias nos problemas de recursos humanos e o maior envolvimento da área de Recursos Humanos com os resultados da empresa — , exigiram, muitas vezes, a adaptação ou criação de políticas que dessem sustentação às estratégias de redução de custos ou de crescimento.

A flexibilização da relação de trabalho, a despeito de todo o aparato legal que o regulamenta, apresentou um crescente número de acordos firmados. Percebe-se um adensamento gradual das pautas em virtude de novas demandas resultantes da reestruturação desencadeada com o processo de abertura da economia brasileira à competição internacional ( Salerno 1996).

\subsection{O novo paradigma produtivo e seus reflexos nas novas relações de trabalho}

Soares (1992), ao tratar das origens da organização da produção industrial neste século, argumenta que todas as empresas estiveram calcadas no modelo taylorista caracterizado "pela atomização das tarefas e separação entre as atividades de organização e métodos que concebem e organizam as atividade de execução. Dessa lógica de trabalho taylorista - sequiência exata de movimentos que são executados pelos operários e suas ferramentas em tarefas subdivididas, 
elementares e parceladas - nasceu o fordismo, como uma forma organizacional distinta e um processo de produção mais complexo" $(\mathrm{p}, 10)$.

O modelo de produção introduzido por Henry Ford teve como função a superação de uma concepção de produção anterior: a produção artesanal. Womack, Jones, Roos (1992) destacam, ainda, que a linha de montagem desenvolvida por Ford ao mesmo tempo que aumentou o volume de produção, reduziu "o esforço humano necessário para montar um automóvel. Além disso, quanto mais veículos Ford produzia, mais o custo por veículo caía". Em termos quantitativos, quando o novo modelo atingiu o seu pico de produção na década de 20 , foram fabricados "2 milhões de veículos iguais num ano" havendo uma redução de mais de $2 / 3$ do custo real para o consumidor (p.17).

Ferreira (1993) destaca três eixos principais que explicam a crise do paradigma tayloristafordista: “(i) a revolução tecnológica (também conhecida como 'terceira revolução industrial'); (ii) as mudanças de caráter organizacional que se traduzem no surgimento de princípios inovadores em matéria de organização do trabalho e da produção em geral; (iii) as mudanças nos mercados de produtos e, em decorrência, nas formas de organização inter capitalista".

Entre os aspectos levantados, o último, que diz respeito a mudanças nos mercados, ajuda a evidenciar as condições extra-firma que contribuíram com a erosão do sistema. Os limites da produção em massa ocorreram em função do crescimento mais lento apresentado a partir dos anos 70 e da instabilidade na demanda. Ferreira ressalta que "as capacidades instaladas tanto a nível nacional, quanto mundial são, em vários setores chave, superiores ao nível da procura” (p.12).

Em toda era fordista, a produção em massa cumpria o papel de abastecer uma demanda potencialmente crescente, sem instabilidade ou flutuações negativas. $O$ novo padrão de concorrência ditado pela alteração da demanda impôs às empresas, outros fatores além do custo. Os mercados passam a exigir então qualidade e diferenciação de produtos.

Ferreira argumenta que deste modo "a qualidade se tornou um determinante da competitividade", assim como a diferenciação. "Tais mudanças implicam na condenação - por inadequação às novas condições de mercado e competitividade - dos sistemas rígidos, e na tendência crescente a busca de esquemas flexíveis de produção capazes de se adaptar a volatilidade e diversificação da demanda" (p.13).

$\mathrm{Na}$ indústria automobilística, incluindo as da região do $\mathrm{ABC}$ Paulista, onde existe grande concentração destas, as mudanças do caráter da organização do trabalho e da produção, tem sofrido profundas mudanças nos últimos tempos, mergulhando em uma guerra de competitividade que tem gerado demissões em massa, causadas, em sua maioria, pelos avanços tecnológicos e pelas mudanças nas relações de trabalho. Se por um lado esses avanços acarretam pontos negativos, por 
outro fazem com que o profissional se torne mais especialista, aprendendo a controlar a máquina e utilizando-a para facilitar a realização de suas tarefas.

Desenvolvimento de iniciativas por parte de todos os empregados, maior necessidade de treinamento e desenvolvimento no campo técnico e acadêmico, necessidade de empregados polivalentes, multifuncionais, que busquem constante aprimoramento, desenvolvendo habilidades de inter-relacionamento pessoal. Estas são algumas das principais alterações que estão ocorrendo nas funções da indústria automobilística, ocasionadas pelas mudanças nas técnicas gerenciais, segundo a área de RH da General Motors do Brasil. "Todas as empresas, e a indústria automobilística em particular, estão em busca de produtividade, o que exige maior investimento, pois sem ele qualquer empresa sucumbe à competição mais aguda, seja ela externa ou interna", diz Fernando Tadeu Perez, diretor de RH da Volkswagen do Brasil.

Com a crescente abertura econômica e tecnológica e o término da reserva de mercado, a indústria precisou buscar a modernização para poder ter condições de competir com o mercado externo. O mercado dita as regras, exigindo veículos mais modernos e baratos, o que obriga as empresas a reduzirem seus custos. Para Osmani Teixeira de Abreu, diretor de relações trabalhistas da Fiat Automóveis, as mudanças gerenciais e os avanços geraram alterações que formam uma regra para toda a indústria. As montadoras, na sua opinião, chegaram mais cedo a esse patamar, mas a indústria, de um modo geral, caminha para isso. Na Fiat optou-se por diminuir um nível gerencial, seguindo uma tendência de redução de níveis que atinge toda a indústria. "O melhor é que reduzimos esse nível sem demissões, aproveitando as pessoas para desenvolverem atividades técnicas, pois eram profissionais especializados", conta Abreu.

Conforme Womack (1992), “o número de níveis hierárquicos na indústria brasileira está muito acima do encontrado em outros países. Isto dificulta sobremaneira o processo de redução de barreiras hierárquicas e de melhoria das comunicações e do fluxo de informações". "Para as empresas, os ganhos se refletem em produtivismo, e para os empregados se revertem em forma de conhecimento e performance. Para o país, gera competitividade internacional e melhora de qualidade", diz Odair Montanaro Gazzetta, executivo de RH e relações institucionais da Toyota.

Segundo o departamento de RH da General Motors, houve a necessidade de efetuar redução nos quadros de empregados, seja para ajustar o efetivo em um ambiente de maior produtividade, seja por necessidade de dispensa daqueles que não se adaptam às novas necessidades. Mas empregados mais preparados significam maior produtividade.

Para Luís Adelar Scheuer, diretor de RH e relações institucionais da Mercedes-Benz, o maior ganho é o da possibilidade do potencial humano ser revelado e fazer com que o indivíduo participe das decisões da empresa. Com relação às perdas, a mudança não traz nenhuma, o que traz perdas é o processo de automação, que gera desemprego. 


\subsection{As teorias X e Y de Douglas McGregor e as tendências na gestão de pessoas}

Segundo McGregor a base de todas as decisões de qualquer dirigente seja qual for o seu posicionamento hierárquico, encontram-se convicções a respeito da natureza do comportamento humano.A teoria $\mathrm{X}$ considera a capacidade da maior parte das pessoas improvável e não muito expressiva.

De acordo com essa teoria o trabalho só será produtivo se for encontrado algo que compense as deficiências mais comuns, tais como julgamento errôneo, passividade e irresponsabilidade.A teoria Y baseia-se na observação de que muitas pessoas, sob condições corretas, poderia descobrir suficiente satisfação no trabalho passando a despender mais esforço do que em resposta somente a coerção.

De acordo com McGregor, pode ser expressa da seguinte a maneira as mudanças nos paradigmas organizacionais:

Quadro 1 : Paradigmas Organizacionais

\begin{tabular}{|l|l|l|}
\hline Década 70 & Década 80 & Década 90 \\
\hline $\begin{array}{l}\text { 1) Organização formal e } \\
\text { hierarquia rígida. }\end{array}$ & $\begin{array}{l}\text { 1) Organograma com } \\
\text { comunicações informais. }\end{array}$ & $\begin{array}{l}\text { 1) Organograma com visão } \\
\text { sistemática. }\end{array}$ \\
\hline $\begin{array}{l}\text { 2) A empresa é o mais } \\
\text { importante. }\end{array}$ & $\begin{array}{l}\text { 2) O empresário é o mais } \\
\text { importante. }\end{array}$ & 2) O homem é o mais importante. \\
\hline $\begin{array}{l}\text { 3) Centralização e metas } \\
\text { impostas. }\end{array}$ & $\begin{array}{l}\text { 3) Descentralização parcial e } \\
\text { conjugação de esforços. }\end{array}$ & $\begin{array}{l}\text { 3) Descentralização plena e ética } \\
\text { das organizações. }\end{array}$ \\
\hline $\begin{array}{l}\text { 4) Administração controladora. } \\
\text { 4) Administração por atividade. }\end{array}$ & $\begin{array}{l}\text { 4) Administração por objetivo e } \\
\text { teste do lucro. }\end{array}$ \\
\hline $\begin{array}{l}\text { 5) Projeto em busca da } \\
\text { estabilidade. }\end{array}$ & 5) Projeto com abertura e riscos. & $\begin{array}{l}\text { 5) Projeto em série - atividades } \\
\text { empreendedoras. }\end{array}$ \\
\hline $\begin{array}{l}\text { 6) Informatizar a qualquer custo. } \\
\text { 7) O\&M normativo e } \\
\text { organizacional. }\end{array}$ & 6) Organizar para informatizar. & $\begin{array}{l}\text { 6) Organizar, informatizar e } \\
\text { treinar. }\end{array}$ \\
\hline Fonte: Heil et al, 2002 & $\begin{array}{l}\text { 7) O\&M normativo, } \\
\text { organizacional e informatizado. }\end{array}$ & $\begin{array}{l}\text { 7) O\&M com enfoque para a } \\
\text { qualidade e sistemas. }\end{array}$ \\
\hline
\end{tabular}

Seguindo essa transição no paradigma organizacional ao longo das três últimas décadas, pode-se alegar que a transformação da organização na época da sociedade industrial, onde a visão mecanicista do empregado, controlado e obediente foi substituída pela sociedade do conhecimento, onde o mesmo apresenta talento humano, constante processo de aprendizagem, participação e cooperação.

O novo foco do desafio na gestão de pessoas é substituir a visão tradicional de que pessoas são recursos semelhantes aos demais por pessoas que aprendem e fazem o diferencial competitivo entre empresas. 


\subsection{Um quadro evolutivo.}

Analisando as características do toyotismo, características estas fortemente presente na indústria automobilística, uma das principais diferenças que sobressaem com relação ao fordismo é a prioridade da equipe sobre o indivíduo. No toyotismo é necessário trabalhar em grupo, porque a produção é organizada em minifábricas, e também devido à complexidade obtida nas linhas de produção a partir dos avanços da eletrônica e mecatrônica. Portanto, na solução de determinados problemas somente o trabalho em equipe é viável.

Por outro lado, o trabalho em equipe, através da execução de um grupo de diferentes atividades, permite ao trabalhador uma visão mais ampla das atividades que executa e, portanto, da sua participação no processo produtivo.

O processo de comunicação é ampliado no sistema Toyota de produção, na medida em que a participação dos operários em termos de maior co-responsabilidade exige que ele tenha maiores informações sobre o sistema produtivo, tanto em termos de procedimentos como de necessidades e números de produção e qualidade.

\begin{tabular}{|c|c|c|c|}
\hline & TAYLORISMO & FORDISMO & TOYOTISMO \\
\hline TRABALHO & $\begin{array}{l}\text { Parcelarizaçào de } \\
\text { tarefas }\end{array}$ & $\begin{array}{l}\text { Parcelarizaça de } \\
\text { tarefas (unica e } \\
\text { especifica) }\end{array}$ & $\begin{array}{l}\text { Multifuncicnal } \\
\text { (muitas tarefas) }\end{array}$ \\
\hline DIVISAO & $\begin{array}{l}\text { Concepcào e } \\
\text { execuçào }\end{array}$ & $\begin{array}{l}\text { Concepça e } \\
\text { execuçào }\end{array}$ & Polifunciznalidade \\
\hline QUALIFICACAO & Pouca cu nerhuma & $\begin{array}{l}\text { Msdia (treinamen- } \\
\text { tos iniciais) }\end{array}$ & $\begin{array}{l}\text { Longo perícdo de } \\
\text { treinamento }\end{array}$ \\
\hline $\begin{array}{l}\text { TIPO DE } \\
\text { TRABALHO }\end{array}$ & Manual & $\begin{array}{l}\text { Manualinformati- } \\
\text { zado }\end{array}$ & Informatizado \\
\hline CONTROLE & $\begin{array}{l}\text { Mestres } \\
\text { (administradores) }\end{array}$ & $\begin{array}{l}\text { Administradores e } \\
\text { esteira rolante (linha } \\
\text { de montagem) }\end{array}$ & $\begin{array}{l}\text { Oriundo dos } \\
\text { proprios cperarios }\end{array}$ \\
\hline $\begin{array}{l}\text { GESTAO } \\
\text { ADMINISTRATIVA }\end{array}$ & $\begin{array}{l}\text { Escritorio + mes- } \\
\text { tres na produryào }\end{array}$ & $\begin{array}{l}\text { Escritçio + } \\
\text { mestres + gestäo } \\
\text { informatizada }\end{array}$ & $\begin{array}{l}\text { Feita pelos patródese } \\
\text { cperários com assis- } \\
\text { tencia de escritorio }\end{array}$ \\
\hline $\begin{array}{l}\text { PROCESSO DE } \\
\text { PRODUÇAO }\end{array}$ & Produçăo em serie & $\begin{array}{l}\text { Produçáo em massa } \\
\text { e em serie de berrs } \\
\text { homogeneos }\end{array}$ & $\begin{array}{l}\text { Produçào em } \\
\text { pequenos lates }\end{array}$ \\
\hline QUALIDADE & $\begin{array}{l}\text { Nào há preccupe- } \\
\text { ça direta }\end{array}$ & $\begin{array}{l}\text { Ha preocupeçà, } \\
\text { porem, os defeitos } \\
\text { ficam coultados }\end{array}$ & $\begin{array}{l}\text { Grande preocupa- } \\
\text { çáo (rejeiçào } \\
\text { imediata das } \\
\text { peças defeitucsas) }\end{array}$ \\
\hline $\begin{array}{l}\text { ORGANIZACAO } \\
\text { PRODUTIVA }\end{array}$ & Năo hâ & $\begin{array}{l}\text { Integaçào vertical e } \\
\text { horizontal }\end{array}$ & $\begin{array}{l}\text { Integraşa vertical } \\
\text { com subcontrataçås }\end{array}$ \\
\hline
\end{tabular}

Fonte: Barros (1998) 
Nota-se que as principais características apresentadas na produção flexível formaram também as principais características dos modelos de relacionamento humano e na gestão de pessoas.

A produção flexível necessita de profissionais e normas de regulação do trabalho flexíveis.

O emprego também está passando uma estruturação idêntica ao Just in Time aplicado na produção. Os trabalhadores estão executando tarefas de acordo com as necessidades demandadas pelos processos produtivos.

Segundo Bridges (2002), "a nova força de trabalho Just in Time deve ser fluída, flexível, onde as empresas não contratam mais funcionários única e simplesmente para executar uma tarefa e sim com o intuito de buscar soluções, idéias e novos negócios".

Neste sentido, Rifkin (1995) coloca que no modelo de produção em massa, pesquisa e desenvolvimento eram separados da fábrica e colocados em um laboratório. Sob o novo sistema de produção enxuta, a fábrica torna-se efetivamente o laboratório de pesquisa e desenvolvimento em um lugar onde a combinação da experiência de cada um é utilizada para aperfeiçoamento contínuo no processo de produção.

A informação, componente importante para nova relação de trabalho e produção, recebe uma valoração maior do que o produto físico. A vantagem competitiva está no conhecimento das pessoas, cujo capital intelectual passa a ser o diferencial entre as empresas.

Sob a ótica das organizações, os fatores terra, trabalho, matéria prima e capital são considerados recursos finitos enquanto que o conhecimento é inexaurível e renovável.

\section{Modelo de avaliação.}

A fim de avaliar as alterações ocorridas em função da globalização, foi enviado um questionário contendo 7 perguntas objetivas envolvendo algumas empresas automobilísticas e de auto peças da região do ABC paulista.

As questões envolvem assuntos inerentes às mudanças na formação escolar dos trabalhadores, formas de remuneração, relações no trabalho e qualificação.

A amostra da pesquisa é significativa, dado que 4 de 5 grandes montadoras da região (Volkswagen, Daimler Chrysler, General Motors e Karmannghia) responderam o questionário. O mesmo questionário fora enviado para 5 grandes empresas do setor de auto peças fornecedoras de $1^{\circ}$ nível destas mesmas montadoras.

As questões formuladas encontram-se no quadro anexo. 


\section{Exemplo ilustrativo.}

\subsection{Apresentação do setor automotivo.}

A indústria automobilística no Brasil iniciou-se em meados da década de 50, com a implantação das fábricas da Mercedes-Benz, Volkswagen, Ford, Scania e Toyota, na região da grande São Paulo (ABCD), onde, em conseqüência, também foi criado um grande parque de fabricantes de autopeças.

Somente na década de 70 surgiram novas fábricas de veículos fora da região do $A B C D$, com as unidades da Volkswagen e da GM, no Vale do Paraíba, a Volvo (fábrica de caminhões e ônibus) no Paraná e a Fiat em Minas Gerais.

A abertura comercial ocorrida nos anos 90 fez com que vários investimentos fossem decididos para a região, considerando o crescimento do mercado interno e a integração Brasil Argentina. Aliada à questão econômica, a pressão exercida pela concorrência mundial obrigou as montadoras a reduzir custos, racionalizar atividades e aumentar a variedade de produtos.

\subsection{Descrição das empresas analisadas.}

Foram analisadas as seguintes montadoras de veículos:

Volkswagen, Daimler Chrysler e General Motors são empresas montadoras já consolidadas no mercado.

A Karmannghia é montadora do veículo utilitário Defender no Brasil, além de fornecer serviços de estamparia, ferramentaria e montagem para a indústria automobilística.

Foram analisadas também empresas de autopeças fornecedoras em primeira camada destas mesmas montadoras como:

Toro, Festo, Dana e Parasmo são forncedoras em $1^{\mathrm{o}}$ nível de auto peças e materiais de fixação em geral.

A Pirelli é a maior fornecedora de pneus para a indústria automobilística no Brasil.

\subsection{Análise e discussão.}

Das empresas analisadas, todas apresentam um crescimento no processo de multi funcionalidade dos funcionários desde o início da década de 90. Todas também apresentam aumento no percentual de funcionários com nível superior de ensino em relação ao período analisado.

Quanto à participação dos funcionários nos processos de decisão, sejam estes operacionais ou estratégicos, somente uma empresa (a Volkswagen) manifestou-se negativamente. 
Na adoção do conceito de TPM ( Manutenção Produtiva Total) somente a Toro declarou que não o adota, sendo que vários dos demais fabricantes de auto peças ( Festo, Dana, Parasmo e Pirelli) o fizeram devido à exigências das montadoras. Das empresas que o adotaram, a maioria iniciou a prática deste conceito nos últimos 10 anos, sendo que a Festo já a aplica há mais de 15 anos.

Quanto ao sistema de remuneração variável por meio de Plano de Participação nos Resultados, somente a Toro e a Dana não o adotam, sendo que a maioria das empresas já o adotam há mais de 10 anos.

\section{Conclusão}

O artigo apresentou um panorama da literatura sobre a gestão de relações humanas e as novas posturas das empresas nas relações de trabalho frente ao processo de globalização, propondo um modelo de avaliação para compreender os fatores motivadores das mudanças.

O exemplo ilustrativo, resultante da aplicação do modelo em 9 empresas do setor automotivo localizados na região do ABC paulista, permitiu obter uma visão dos reflexos das mudanças nas relações de trabalho frente ao processo de globalização no setor.

Os resultados obtidos na pesquisa orientam a novas exigências no ambiente de trabalho. $\mathrm{O}$ funcionário que antes tinha como obrigação apenas a repetição de tarefas em série, atualmente é cobrado deste a criação de soluções a melhorias de resultado (maximização da produção e redução de custos).

Antigamente os funcionários trabalhavam em função de uma tarefa, hoje visualiza-se um projeto. Em alguns níveis executivos e até mesmo gerenciais e analíticos, aumentou-se a remuneração variável em função de resultados ao invés da tradicional remuneração fixa.

Cresce atualmente a parcela variável na remuneração do profissional. Esta remuneração é feita através de metas atingidas, obrigando o profissional a buscar cada vez mais melhorias em seus projetos, trabalho em equipe e visão de produto e resultado. Os profissionais de uma empresa não podem ter mais aquela visão curta de departamento e sim uma visão abrangente da empresa como um todo e conhecimento de seu produto.

\section{Abstract}

This article aims at to approach the occured alterations in the management of Human resources in the industries face to the globalization and its consequences in the forms of relation of the work, considering its complexity and its consequent conflicts and the increasing degree of competitiveness. In particular, the recent changes in the relations of work in the automobile industries and auto parts of the São Paulo ABC are analyzed, comparing it Scientific Administration of Taylor with the current toyotist environment. 
It is studied as this process of adjustment, exacerbated in the decade of 1990, comes elucidating new trends in the relations of work of the analyzed category, configuring important changes, clearly as for the relation of work and its new requirements.

This work intend to bring some reflections on the new productive necessities front to the competitive market, presenting a illustrative example, gotten on the basis of the preliminary results of a in progress research involving located companies of the automotive sector in the region of the Great São Paulo and the Great ABC.

Key words: work.; globalization.; human resources

\section{Referências}

BARROS, L.A. O "novo" e o "velho": O trabalho e o processo produtivo em discussão. Revista de Ciências Sociais e Humanas da Universidade Metodista de Piracicaba. Piracicaba - SP. V.10 nº 22/23. pg 93. 1998

BRIDGES, William - Um Mundo sem Empregos - São Paulo; 1995 Makron Books

CORIAT, Benjamin. Pensar pelo Avesso: o modelo japonês de trabalho

e organização. Rio de Janeiro: Revan/UFRJ, 1994.

FERREIRA, C. O fordismo, sua crise e o caso brasileiro. Cadernos do Cesit: texto para discussão n. 13. Universidade de Campinas, 1993.

FORD, Henry. Minha Vida e Minha Obra. Rio de Janeiro/São Paulo:

Companhia Editora Nacional, 1926.

HEIL, G. BENNIS, W. STEPHENS, D. Douglas McGregor em Foco: Gerenciando o Lado Humano da Empresa Rio de Janeiro - RJ Ed. Qualitymark 2002

RIFKIN, Jeremy - O fim dos empregos - São Paulo,1995 Makron Books

SALERNO, M. Organização do trabalho, trabalho real e eficiência em sistemas flexíveis. in Padrões tecnológicos, trabalho e dinâmica espacial. José Augusto Fortes e Rosa Maria Soares, (org.), tradução de Frank Soudant. UnB, Brasília, 1996.

SOARES, R.M. Mudança tecnológica e dimensão organizacional: premissas para a qualidade e produtividade. in Gestão da qualidade: tecnologia e participação. Rosa Maria S. M. Soares (org.). Brasília: Codeplan, 1992. (Série Cadernos Codeplan; 1).

TAYLOR, Frederick. Princípios de Administração Científica. São Paulo: Atlas, 1970.

WOMACK, J. P. JONES, A Máquina que Mudou o Mundo Rio de Janeiro 1992.

\section{ANEXOS}

\section{QUESTÕES}

1 - Atualmente existem mais funcionários (em percentual do total de funcionários) nesta empresa com características multifuncionais (polivalentes) do que no início da década de 90 ?

$\operatorname{SIM}(\quad)$ $\mathrm{NÃO}(\quad)$ 
2 - Atualmente existem mais funcionários (em percentual do total de funcionários) nesta empresa com formação superior do que no início da década de 90 ?
$\operatorname{SIM}(\quad)$
$\mathrm{NA} O(\quad)$

3 - Atualmente existem mais funcionários (em percentual do total de funcionários) nesta empresa que participam das decisões (estratégicas ou operacionais) do que no início da década de 90 ?

$\operatorname{SIM}(\quad)$

$\mathrm{NÃO}(\quad)$

4 - Atualmente esta empresa adota o conceito de TPM (Manutenção Produtiva Total)?

$\operatorname{SIM}(\quad)$

$\mathrm{NÃO}(\quad)$

5 - Se sim, em que ano esta empresa adotou o conceito de TPM (Manutenção Produtiva Total)?

6 - Atualmente existem mais funcionários (em percentual do total de funcionários) nesta empresa que fazem parte de planos de participação nos resultados ( salário variável) do que no início da década de 90 ?

$\operatorname{SIM}(\quad)$

$\mathrm{NÃO}(\quad)$

7 - Se sim, em que ano esta empresa adotou o plano de participação nos resultados? 
Tabulação dos resultados

\begin{tabular}{|c|c|c|c|c|c|c|c|c|c|}
\hline & Toro & GM & karmannghia & Festo & Dana & VW & Parasmo & $\begin{array}{l}\text { Daimler } \\
\text { Chrysler }\end{array}$ & Pirelli \\
\hline 1 & $S$ & $S$ & $S$ & $S$ & $S$ & $S$ & $S$ & $S$ & $S$ \\
\hline 2 & $\mathrm{~s}$ & $\mathrm{~s}$ & $\mathrm{~s}$ & $\mathrm{~S}$ & $\mathrm{~s}$ & $\mathrm{~s}$ & $\mathrm{~s}$ & $\mathrm{~S}$ & $\mathrm{~s}$ \\
\hline 3 & $S$ & $S$ & $S$ & $S$ & $S$ & $\mathrm{n}$ & $S$ & $S$ & $S$ \\
\hline 4 & $\mathrm{n}$ & $S$ & $\mathrm{~S}$ & $\mathrm{~S}$ & $S$ & $\mathrm{~S}$ & $\mathrm{~S}$ & $\mathrm{~S}$ & $S$ \\
\hline 5 & & 1995 & 2003 & 1990 & 2000 & 1995 & 1998 & 1997 & 1994 \\
\hline 6 & $n$ & $S$ & $S$ & $S$ & $\mathrm{n}$ & $S$ & $S$ & $\mathrm{~S}$ & $S$ \\
\hline 7 & & 1995 & 2000 & 1995 & & 1995 & 1996 & 1995 & 1995 \\
\hline
\end{tabular}

$\mathrm{s}=\operatorname{sim}$

$\mathrm{n}=$ não

em branco = não aplicável 


\section{Dados dos autores:}

Nome completo: Marcos José Corrêa Bueno

Filiação institucional: Universidade Bandeirantes UNIBAN

Departamento: Logística

Função: Professor

Endereço: Av Sem Vitorino Freire, 180 Bl C ap 41 Jd Melo São Paulo SP Brasil cep 04423000

Telefone: 01156223836

e-mail: mjvm@ig.com.br

Nome completo: Oduvaldo Vendrametto

Filiação institucional: Universidade Paulista UNIP

Departamento: Mestrado

Função: Coordenador

Endereço: Rua Caiowá, 2046 Ap 62 B1 2 Perdizes São Paulo SP Brasil cep 01250 - 010

Telefone: 01138712550

e-mail: oduvaldov@uol.com.br

Nome completo: Alexandre Alisancic

Filiação institucional: Faculdade Flamingo

Departamento: Logística e Produção

Função: Professor

Endereço: Rua Acre, 292 Jd Imperador Guarulhos SP Brasil cep 07064 - 010

e-mail: alisancic@bol.com.br

Recebido para publicação em: 16/03/07

Aceito para publicação em: 22/05/07 